DOI: $10.14451 / 1.166 .125$

\title{
АНАЛИЗ ОПЫТА СТРАН-УЧАСТНИЦ ЕВРАЗИЙСКОГО ЭКОНОМИЧЕСКОГО СОЮЗА В ЧАСТИ ИСПОЛЬЗОВАНИЯ МЕХАНИЗМА И ИНСТРУМЕНТОВ ДОЭК ОЭСР *
}

\author{
(c) 2018 Карпов Валерий Васильевич \\ доктор экономических наук, профессор кафедры «Финансы и кредит» \\ Омский филиал Финансового университета при Правительстве Российской Федерации \\ 644099, г. Омск, ул. Партизанская, 6 \\ E-mail: Karpov-V51@yandex.ru \\ (c) 2018 Хаиров Бари Галимович \\ доктор экономических наук, доцент, заместитель директора по научной работе \\ Омский филиал Финансового университета при Правительстве Российской Федерации \\ 644099, г. Омск, ул. Партизанская, 6 \\ E-mail: hairov@bk.ru

\section{(c) 2018 Миллер Елена Валерьевна} \\ старший преподаватель \\ Омский филиал Финансового университета при Правительстве Российской Федерации \\ 644099, г. Омск, ул. Партизанская, 6

\section{(c) 2018 Миллер Максим Александрович} \\ доктор экономических наук, доцент \\ профессор кафедры «Экономика и управление человеческими ресурсами» \\ Омский государственный университет имени Ф.М. Достоевского \\ 644077, г. Омск, пр. Мира, 55а \\ E-mail:millerma@yandex.ru
}

В статье рассматривается сущность механизма и инструментов Договоренности ОЭСР по официально поддерживаемым экспортным кредитам. Авторами проведен анализ практики применения механизма ДОЭК странами-участницами ЕАЭС. В статье рассмотрены законодательные основы, регулирующие государственную поддержку экспорта в странах ЕАЭС и сделаны выводы о соответствии правовой базы требованиям и нормам ДОЭК.

Ключевые слова: ДОЭК ОЭСР, государственная поддержка экспорта, механизм ДОЭК ОЭСР, экспортное кредитование, инструменты ДОЭК ОЭСР, страхование экспортного кредита, государственные гарантии, законодательная база.

На сегодняшний день одной из задач договора стран-участниц Евразийского экономического союза (далее - ЕАЭС) является реализация мер по развитию экспорта в соответствии с международными правилами. Однако для стран, входящих во Всемирную торговую организацию (далее - ВТО), предоставление промышленных субсидий, связанных с результатами экспорта, является запрещенной мерой. Договоренность Организаций экономического сотрудничества и развития (далее - ОЭСР) по официально поддерживаемым экспортным кредитам (далее ДОЭК ОЭСР) позволяет странам, в том числе и не входящим в ВТО, а также в ОЭСР, использо- вать практику экспортного кредитования и оказывать государственную поддержку экспортных кредитов, не нарушая при этом требования ВТО.

ДОЭК ОЭСР является механизмом обеспечения равных условий конкуренции между институтами поддержки экспорта и сдерживания попыток нарушения баланса на рынке [2]. Договоренность является бессрочной, вступила в силу в апреле 1978 года и с тех пор претерпела ряд изменений (последние из них внесены от 01.01.18). ДОЭК не является актом ОЭСР, а «джентльменским соглашением», это определено статьей 2 самого документа ДОЭК [1].

Механизм ДОЭК основан на кредитовании

\footnotetext{
* Статья подготовлена по результатам исследований, выполненных за счет бюджетных средств по государственному заданию Финуниверситету 2018 года
} 
иностранного покупателя или банка покупателя для приобретения продукции экспортера. Кредитором выступает финансовый институт, имеющий полномочия согласно законодательству той или иной страны, предоставляя кредит иностранному покупателю на приобретение промышленной продукции. В рамках механизма ДОЭК предусмотрены основные дополнительные условия государственной поддержки экспортных кредитов: срок кредитования (статья 11-13 ДОЭК) от 2 лет до 10 лет, для неядерных электростанций срок погашения составляет 12 лет; авансовый платеж должен быть не менее 15\% стоимости всего контракта до предоставления финансирования (статья 10 ДОЭК); участники не должны предоставлять официальную поддержку сверх 85\% стоимости экспортного контракта (статья 10 ДОЭК); соглашения не распространяется на экспорт военной техники и сельскохозяйственной продукции (статья 5 ДОЭК). Основу механизма ДОЭК составляют основные инструменты государственной поддержки экспорта, которые выражаются в следующих формах субсидирования экспорта (статья 5 ДОЭК ОЭСР): страхование экспортного кредита или предоставление государственной гарантии; две формы государственной финансовой поддержки (первая - прямой кредит или рефинансирование (по прямому кредитованию экспортные агентства обеспечивают прямое кредитование заемщику с учетом ставки CIRR процентная ставка, рассчитываемая на основе стоимости государственных заимствований и надбавки к базисной ставке процента); вторая компенсация части процентной ставки (специальные программы, по которым государство возмещает кредитору разницу между рыночными процентными ставками и льготными ставками по экспортным кредитам)); сочетание любых из вышеперечисленных форм [1].

Выделение механизма и инструментов ДОЭК ОЭСР дает возможность провести анализ опыта их применения странами-участницами ЕАЭС. Применение мер по развитию экспорта, соответствие международным нормам и правилам должно основываться на соответствующей законодательной базе каждой страны. Следовательно, в странах ЕАЭС должны быть заложены правовые основы, учитывающей требования ВТО и ДОЭК ОЭСР. Законодательная база стран-участниц ЕАЭС представлена в табл. 1.

Нормативно-правовая база, регулирующая государственную поддержку экспорта согласно требованиям ДОЭК, заметно отличается в указанных странах. Так, в России (далее - РФ) законодательные основы шире и более детализированы, а также напрямую касаются экспортного финансирования согласно требованиям Договоренности. Однако можно отметить существенные недостатки и противоречия законодательных основ в РФ.

Так, законодательством не предусмотрено предоставление минимального размера аванса, что исходит из условий ДОЭК. В Концепции

Таблица 1. Соответствие законодательных норм требованиям ДОЭК в странах-участницах ЕАЭС

\begin{tabular}{|c|c|}
\hline Страны & Правовые основы, регулирующими экспортное кредитование в рамках ДОЭК \\
\hline РФ & $\begin{array}{l}\text { - Концепция развития государственной финансовой (гарантийной) поддержки экспорта } \\
\text { промышленной продукции в Российской Федерации (от } 14.10 .2003 \text { г. № } 1493-\text { p) (далее - Кон- } \\
\text { цепция); } \\
\text { - Постановление Правительства РФ от } 24.05 .2017 \text { г. № } 620 \text { «Об утверждении Правил предо- } \\
\text { ставления из федерального бюджета субсидии акционерному обществу «Российский экспорт- } \\
\text { ный центр» на цели субсидирования процентных ставок по экспортным кредитам, предостав- } \\
\text { ляемым коммерческими банками»; } \\
\text { - Постановлении Правительства от } 30.03 .2018 \text { г. № } 376 \text { «О внесении изменений в государ- } \\
\text { ственную программу Российской Федерации «Развитие внешнеэкономической деятельности»» }\end{array}$ \\
\hline $\mathrm{PK}$ & $\begin{array}{l}\text { - Кодекс РК от 29.10.2015 года № 375-V Предпринимательский кодекс Республик Казахстан; } \\
\text { - Постановление Правительства Республики Казахстан от 26.08.2017 года № } 511 \text { «Об утверж- } \\
\text { дении Программы «Национальная экспортная стратегия» РК на 2018-2022 годы»; Программа } \\
\text { «Дорожная карта бизнеса 2020» }\end{array}$ \\
\hline РБ & $\begin{array}{l}\text { Указ Президента Республики Беларусь от 25.08.2006 г. № } 534 \text { «О содействии развитию экспорта } \\
\text { товаров (работ, услуг) и Национальная программа поддержки и развития экспорта на 2016- } \\
2020 \text { гг. }\end{array}$ \\
\hline $\mathrm{PA}$ & $\begin{array}{l}\text { Стратегия экспортоориентированной промышленной политики Армении», утвержденная } \\
\text { Решением Правительства Республики Армения от 15.12.2011 г. № } 149\end{array}$ \\
\hline $\mathrm{KP}$ & $\begin{array}{l}\text { План Правительства Кыргызской Республики по развитию экспорта Кыргызской Республики } \\
\text { на 2015-2017 гг. и Программа по переходу Кыргызской Республики к устойчивому развитию на } \\
\text { 2013-2017 гг. }\end{array}$ \\
\hline
\end{tabular}


предусмотрено 100\% экспортное кредитование за счет средств федерального бюджета в целях реализации приоритетных экспортных проектов, что расходится с нормами ДОЭК. Кроме того, в ней подробно представлены основные инструменты поддержки экспорта, но не рассмотрено страхование экспортных кредитов [5]. А также, следует обратить внимание, на Постановление Правительства № 376, в котором не отражены объемы средств на экспортные кредиты, предоставляемые импортерам или банкам импортера в рамках целевых показателей и индикаторов государственной программы РФ до 2020 г. [11]. Если рассматривать Постановление Правительства № 620 и изменения к нему в Постановлении Правительства № 692 (далее Постановление № 692) на предмет соответствия требованиям ДОЭК ОЭСР, то следует отметить несовпадение сроков финансирования. В Постановлении № 692 указано об экспортном кредитовании сроком до 2 лет, в то время как в требованиях ДОЭК речь идет только о среднесрочном и долгосрочном кредитовании (не менее 2 лет) $[9,10]$.

В Республике Казахстан (далее - PK) в нормативно-правовом поле, представленном в табл. 1 , уделяется мало внимания вопросам экспортного кредитования в рамках ДОЭК. Предпринимательский Кодекс PK не затрагивает данные вопросы. Механизмы и инструменты ДОЭК не рассмотрены в нормативах Республики Казахстан. Лишь в «Национальной экспортной стратегии» говорится о возможности экспортного кредитования с учетом ограничений, предусмотренных в рамках ВТО на уровне справочной коммерческой процентной ставки CIRR. В данном же документе отмечается только поддержка экспортеров по требованиям двух финансовых институтов (АО «БРК» и АО «БРК-Лизинг»), наделенных полномочиями кредитования нерезидента, приобретающего казахстанскую продукцию [8].

В Республике Беларусь (далее - РБ), не являющейся пока членом ВТО, Указом Президента «О содействии развитию экспорта товаров (работ, услуг)» соответствие нормам ДОЭК установлено частично только в п. 3.1., в котором определено 85\% финансирования экспортных контрактов и применение коммерчески ориентированных процентных ставок (CIRRs). В остальном нормативная база РБ ориентирована на страховании экспортных рисков с поддержкой государства
[13].

Следует отметить, что законодательная база в Республике Армении (далее - РА) не определяет основы функционирования финансовых институтов и финансовых инструментов в рамках ДОЭК, что существенно тормозит развитие экспорта в данном направлении и противоречит нормам ВТО. Это же можно отметить и в законодательных основах Кыргызской Республики (далее - КР), в которых затрагивают лишь отдельные вопросы экспорта, но не учитываются требования и нормы ДОЭК. Кроме того, видно, что нормативная база КР является не актуальной и требует изменений с учетом современных тенденций и требований ВТО [4].

Согласно сформированным законодательным основам в странах-участницах ЕАЭС можно определить основные финансовые инструменты и институты поддержки экспорта согласно ДОЭК (табл. 2).

В РФ используются все основные формы государственной поддержки экспорта и сформирован комплекс финансовых институтов. Как показал анализ механизма экспортного кредитования согласно требованиям ДОЭК ОЭСР, осуществляемая в России финансовая поддержка экспортеров не во всем соответствует нормам, а именно: в основном (как показали практические примеры) уполномоченными финансовыми институтами финансируются проекты, направленные на развитие гражданской авиации и энергетики; в основных условиях прямого кредитования АО «РОСЭКСИМБАНКА» предусмотрено финансирование в размере $100 \%$ от суммы экспортного контракта, что является недопустимым по ДОЭК [12]. Стоит отметить, что в докладе Минпромторга в планах на 2018 г. не идет речи о льготном кредитовании иностранных покупателей, что снижает возможности экспорта [3].

Таким образом, проблему соответствия государственной финансовой поддержки экспорта в РФ международным требованиям можно решить, установив строгое выполнение критериев по ДОЭК, а также предусмотреть в планах Правительства средства, направляемые на льготное кредитование иностранных покупателей с целью повышения привлекательности экспортных контрактов.

В Республике Казахстан сложились свои институциональные особенности обеспечения экспортного кредитования. Основными про- 
Таблица 2. Финансовые институты и формы поддержки экспорта

\begin{tabular}{|c|c|c|c|c|c|}
\hline & $\mathrm{P} \Phi$ & PK & РБ & PA & KP \\
\hline $\begin{array}{c}\text { государственные } \\
\text { гарантии }\end{array}$ & $\begin{array}{c}\text { Минфин РФ, ВЭБ, } \\
\text { АО «Росэксим- } \\
\text { банк» }\end{array}$ & - & $\begin{array}{c}\text { Министерства } \\
\text { финансов РБ }\end{array}$ & - & - \\
\hline $\begin{array}{l}\text { страхование экс- } \\
\text { портного кредита }\end{array}$ & $\begin{array}{c}\mathrm{AO} \text { «ЭКСАР» (груп- } \\
\text { па АО «Россий- } \\
\text { ский экспортный } \\
\text { центр») }\end{array}$ & $\begin{array}{c}\text { Экспортно-кре- } \\
\text { дитная страховая } \\
\text { корпорацией } \\
\text { KazakhExport }\end{array}$ & $\begin{array}{c}\text { Предприятие экс- } \\
\text { портно-импорт- } \\
\text { ного страхования } \\
\text { «Белэксимгарант» }\end{array}$ & $\begin{array}{c}\text { Экспортное стра- } \\
\text { ховое агентство }\end{array}$ & - \\
\hline $\begin{array}{c}\text { прямой кредит } \\
\text { или рефинансиро- } \\
\text { вание }\end{array}$ & $\begin{array}{c}\text { АО «Росэксим- } \\
\text { банк», Внешэко- } \\
\text { номбанк (ВЭБ), }\end{array}$ & $\begin{array}{c}\text { Банк развития } \\
\text { Казахстана (БРК), } \\
\text { дочерняя органи- } \\
\text { зация АО «БРК-Ли- } \\
\text { зинг» }\end{array}$ & $\begin{array}{c}\text { Банка развития Ре- } \\
\text { спублики Беларусь } \\
\text { (БРРБ) }\end{array}$ & - & - \\
\hline $\begin{array}{c}\text { субсидирование } \\
\text { процентных ста- } \\
\text { вок кредитующему } \\
\text { банку }\end{array}$ & $\begin{array}{c}\text { уполномоченные } \\
\text { банки (Банк ВТБ и } \\
\text { ПАО «Сбербанк») }\end{array}$ & - & - & - & - \\
\hline $\begin{array}{c}\text { льготное кредито- } \\
\text { вание иностран- } \\
\text { ных покупателей }\end{array}$ & $\begin{array}{c}\text { Внешэкономбанк } \\
\text { совместно с ОАО } \\
\text { «ЭКСАР» }\end{array}$ & - & - & - & - \\
\hline
\end{tabular}

дуктами БРК в рамках ДОЭК ОЭСР являются: экспортное финансирование, которое включает финансирование банка импортера для оплаты аккредитива, выпуск аккредитива по требованию импортера в пользу экспортера. К недостаткам финансовой поддержки экспорта в PК можно отнести, прежде всего, дороговизну кредитных ресурсов, которая объясняется тем, что экспортеры РК не могут предложить иностранным покупателям казахстанской продукции привлекательные кредитные условия. Так, например, процентные ставки по экспортным кредитам KazakhExport составляют около 9\% годовых в долл. США, что значительно выше предельной ставки CIRR по ДОЭК ОЭСР. Кроме этого, использование аккредитивной формы расчетов, несмотря на её высокую гарантированность, обходится дорого покупателю казахстанской продукции, что снижает привлекательность сделок. А также развитие экспорта тормозит слабое позиционирование казахстанских товаров и услуг, а также малую узнаваемость казахстанских брендов на мировом рынке [6]. Таким образом, в РК в целях продвижения экспорта необходимо рассмотреть возможность удешевления стоимости кредитов и страхования с учетом ограничений, предусмотренных в рамках ВТО, до уровня справочной коммерческой процентной ставки (CIRR) [8].

В Белоруссии создана достаточно узкая институциональная структура поддержки экспорта в рамках ДОЭК. Связано это с тем, что исключительное право реализовывать такой инстру- мент как экспортное кредитование нерезидентов возлагается только на Банк Развития РБ, что говорить о недостаточно развитой системе финансовых институтов и инструментов поддержки экспорта в рамках ДОЭК. К недостаткам можно отнести и ограниченность финансовых ресурсов, направляемых на субсидирование экспорта в длительной перспективе. Учитывая планы Белоруссии по вступлению в ВТО, можно рекомендовать расширить нормативную базу и инструменты финансовой поддержки экспортных кредитов, привлекая при этом и устойчивые коммерческие банки страны [7].

В Республике Армения единственным институтом, созданным для покрытия рисков экспортеров, является «Экспортное страховое агентство». Следует отметить, что нормативная база в Армении не определяет основы функционирования финансовых институтов и финансовых инструментов в рамках ДОЭК, что существенно тормозит развитие экспорта в данном направлении и противоречит нормам ВТО. Кроме этого, в Армении, как показал анализ, нет основного государственного финансового агента, реализующего кредиты иностранным покупателям армянской продукции, а также коммерческие банки не имеют полномочий реализовывать этот инструмент. Кроме этого, можно отметить, что в Армении слабо развита система долгосрочного финансирования в коммерческих банках, что также не может быть сопоставимо с кредитами, привлекаемыми по требованиям ДОЭК [4].

В Кыргызской Республике не используются 
механизмы экспортного кредитования импортеров киргизской продукции, отсутствует механизм поддержки экспортного кредитования в рамках ДОЭК и финансовые институты, реализующие данные механизм [4].

Таким образом, на сегодняшний день институциональные структуры финансовой поддержки экспортных кредитов, осуществляющие данную поддержку согласно ДОЭК ОЭСР, сформировались, прежде всего, в таких странах ЕАЭС, как Россия, Белоруссия и Казахстан. В этих же странах используется большинство инструментов ДОЭК ОЭСР, а также полностью соблюдаются требования по ДОЭК ОЭСР по размеру авансового платежа, уровня процентной ставки с ориентацией на CIRR, сроку кредитования. В Армении и Киргизии общий механизм и инструменты ДОЭК ОЭСР еще находятся в стадии формирования на национальном уровне, что, безусловно, осложняет осуществление в рамках союза скоординированных шагов по развитию конкурентного рыночного пространства ЕЭАС.

\section{Библиографический список}

1. Arrangement on officially supported export credits/ OECD.- URL: http://www.oecd.org/officialdocuments/ publicdisplaydocumentpdf/doclanguage-en\&cote-tad/pg(2018).

2. Данильщев А. В., Савельев О.В. Договоренность ОЭСР по экспортному кредитованию и возможности ее использования в интересах поддержки экспорта // Сборник публикаций «Сотрудничество государств-членов ЕАЭС с ОЭСР в контексте развития интеграционной повестки Союза. Возможности использования наилучших практик ОЭСР в работе ЕАЭС», Москва. 2017 г.

3. Доклад о целях и задачах Минпромторга России на 2018 год и основных результатах деятельности за 2017 год.- Режим доступа: http://minpromtorg.gov.ru/common/upload/docVersions/5ad48d069014f/actual/ Minpromtorg_press2.pdf.

4. Евразийская экономическая комиссия. Департамент промышленной политики. Анализ возможностей продвижения совместно произведенной промышленной продукции государств - членов на экспорт в приоритетных отраслях промышленности. Москва 2017/ http://www.eurasiancommission.org/ru/act/prom_i_ agroprom/dep_prom/SiteAssets/prodv_sovm_proizv_prod.pdf.

5. Концепции развития государственной финансовой (гарантийной) поддержки экспорта промышленной продукции в Российской Федерации (одобрена распоряжением Правительства Российской Федерации от 14 октября 2003 г. № 1493-p) // СПС «Консультант плюс».- Режим доступа: http://www.consultant.ru/

6. Кредитные продуты / Официальный сайт Банка Развития Казахстана. - Режим доступа: https://www.kdb.kz/ $\mathrm{ru} /$ services/finansirovanie-eksportnykh-operatsiy/kreditnye-produkty/

7. Официальный сайт Банк Развития Республик Белоруссия/ Поддержка экспорта. Режим доступа: https://brrb. by/activity/export-support/

8. Постановление Правительства Республики Казахстан от 26 августа 2017 года № 511 «Об утверждении Программы «Национальная экспортная стратегия»» / Информационно-правовая система нормативных правовых актов Республики Казахстан. Режим доступа: http://adilet.zan.kz/rus/docs/P1700000511.

9. Постановление Правительства Российской Федерации от 24 мая 2017 г. № 620 «Об утверждении Правил предоставления из федерального бюджета субсидии акционерному обществу «Российский экспортный центр» на цели субсидирования процентных ставок по экспортным кредитам, предоставляемым коммерческими банками».- Режим доступа: http://www.consultant.ru/

10. Постановление РФ от 16 июня 2018 г. № 692 «О внесении изменений в постановление Правительства Российской Федерации от 24 мая 2017 г. № 620». Режим доступа: http://www.consultant.ru/

11. Постановление Правительства от 30.03.2018 г. № 376 «О внесении изменений в государственную программy Российской Федерации «Развитие внешнеэкономической деятельности»». Режим доступа: http://www. consultant.ru

12. Прямой кредит покупателю/Официальный сайт АО «РОСЭКСИМБАНК».- Режим доступа: http://eximbank. ru/credits/product.php-page-33447

13. Указ Президента Республики Беларусь от 25.08 .2006 г. № 534 «О содействии развитию экспорта товаров (работ, услуг) Режим доступа: http://www.minfin.gov.by/upload/insurance/acts/ukaz_250806_534.pdf. 